\title{
Phasing-out tobacco: proposal to deny access to tobacco for those born from 2000
}

\author{
Deborah Khoo, ${ }^{1}$ Yvonne Chiam, ${ }^{1}$ Priscilla Ng, ${ }^{1}$ AJ Berrick, ${ }^{2}$ HN Koong ${ }^{1}$
}

${ }^{1}$ Department of Surgical Oncology, National Cancer Centre Singapore, Singapore Department of Mathematics, National University of Singapore, Singapore

\section{Correspondence to}

HN Koong, National Cancer Centre Singapore, Department of Surgical Oncology. 11 Hospital Drive, Singapore 169610, Singapore: dsokhn@nccs.com.sg

Received 23 April 2009 Accepted 18 March 2010

\section{(2) UNLOCK:}

This paper is freely available online under the BMJ Journals unlocked scheme, see http:// tobaccocontrol.bmj.com/site/ about/unlocked.xhtml

\section{ABSTRACT}

As a contribution to worldwide efforts towards a tobacco-free society, this paper considers the possibility of a long-term phasing-in of a total ban, by proposing that individuals born in or after the year 2000 have their supply of tobacco restricted. In conjunction, a survey that we have conducted in Singapore indicates strong public support (even among current smokers) for the proposal.

\section{INTRODUCTION}

Tobacco use in the form of smoking has long been recognised as a cause of morbidity and premature mortality, which incurs significant healthcare and economic burdens. ${ }^{1-3}$ It is estimated that it will kill more than eight million people a year by $2030 .{ }^{4}$ Its association with a plethora of cancers, cardiovascular and pulmonary diseases in particular is well established. Tobacco smoke affects not just smokers but also passive recipients of the smoke. Most importantly, it is an eminently preventable problem. There are ongoing efforts to help existing smokers quit, and to educate the public on the detrimental effects of smoking. However, in the area of public health measures, more can and should be done. Given the knowledge that we now have of the ill-effects of tobacco use, tobacco products would almost certainly be rejected if submitted to the relevant authorities for approval as a new product. Yet cigarettes are legally and widely available, owing to the historical accident that commercial companies involved in their manufacture, distribution and sale predate such authorities.

Strategies employed currently to reduce tobacco use have been targeted at both the demand and supply of tobacco. Commonly used measures include public education, warning labels, high taxes, bans on cigarette promotion, programmes to support quitting, smoke-free public places and workplaces, and a fixed minimum age law. These are aimed at preventing smoking initiation among the young, promoting smoking cessation among smokers and protecting non-smokers from the harmful effects of secondhand smoke. In Singapore, for example, such measures have helped to cut down the smoking prevalence rate from $20 \%$ in 1984 to $13.6 \%$ in 2007.5 However, according to the 2007 National Health Surveillance Survey, the adult smoking rate was highest among the youngest cohort-namely, those adults aged 18-29 years, and has increased from $12.3 \%$ in 2004 to $17.2 \%$ in 2007.5

Internationally, the percentage of smokers has been found to increase most rapidly between the ages of 12 and $18 .{ }^{6}$ Given the highly addictive nature of nicotine, ${ }^{7}$ which limits the effectiveness of measures to encourage quitting, this is the group that forms the principal battleground for both sides in the tobacco war. There is a strong trend worldwide for those who started smoking as teenagers to go on to become adult, long-term tobacco users. ${ }^{8-10}$

Unfortunately, the ammunition provided by the measures indicated above seems to be insufficient to prevent young people from taking up the smoking habit. This suggests that, although the synergistic measures of education and legislation, such as policies on awareness, display and promotion, warning labels, taxation, and designated smoking zones, play very important roles and should not be neglected, ${ }^{411} 12$ a significantly novel approach may yet be needed.

\section{CURRENT DIFFICULTIES}

Before describing our proposed approach, we describe reasons why the chief present method of attempting to prevent young people from starting smoking, the fixed minimum age ban, is likely to have limited success. Internationally, the age of demarcation in minimum age law ranges from 16 to 19 years of age, most commonly 18 (as in Singapore). The impact of such bans has been discussed in a government consultation carried out by the UK Department of Health, with the conclusion that the effectiveness of a minimum age law is hampered by the range of cigarette sources available to youths and the degree of cooperation of retailers in enforcing the law. ${ }^{13}$

\section{Impression of 'rite of passage'}

A probable further key reason for the suboptimal effectiveness of such legislation is that the concept is fundamentally flawed: it assumes and implies that smoking belongs to the class of activities (like driving, viewing adult-rated movies and alcohol consumption) for which there is an age when the activity becomes acceptable. Children may thus come to view smoking as a rite of passage, and that under-age prohibitions are intended only to hinder the commencement of smoking up to the age of 18 . The desire to appear grown-up ${ }^{14}$ is also exploited by tobacco advertising and product placement in movies, ${ }^{15}$ which explicitly aim to create the image that smoking is synonymous with becoming adult. Thus, for example, it is claimed that $80 \%$ of movies in the USA rated PG-13 contain tobacco smoking. ${ }^{16}$ The link between smoking and adulthood is inadvertently reinforced by a fixed minimum age ban. ${ }^{6} 10$

\section{Difficulty of enforcement}

A significant current drawback concerns the practical difficulties of enforcement. Age is a dynamic 
number that requires the vendor to perform a mental calculation from the birth date shown on the customer's identity card. This inconvenience may lead the vendor to compromise (especially when busy), with cursory checks such as merely asking a customer whether s/he is 18 (or born before today's date 18 years ago), or agreeing to sell the cigarettes if the customer indicates that it is meant for an adult. ${ }^{17-19}$ In Singapore, the Health Sciences Authority reported an increase in the number of youths under the age of 18 caught smoking in the first 2 months of 2008 compared to the same period in $2007 .^{20}$ There is no consolidated study to ascertain the actual enforcement rate of the under-18 ban, and this may be a worthwhile investigation to obtain statistical data on the extent of the problem. Again, difficulty of implementation may be inevitable, given the flawed concept: if it is legally permissible for an 18-year-old to buy cigarettes, can it really be a serious offence for a 17-year-old to do so too? And is this age difference too slight to make it worthwhile alienating a customer?

\section{ALTERNATIVE STRATEGIES \\ An immediate outright ban}

As noted in the Introduction, tobacco is such a public health hazard that it is only an historical accident that makes its use lawful, almost alone among recreational drugs. A sudden outright ban, however, is very likely to be politically and socially unpalatable. There is likely to be public sympathy for the hardship such a ban imposes on current smokers who, because of the addictive nature of nicotine, will find it difficult to quit. Economically, it has adverse acute effects through the supply chain. Politically, the sudden loss of excise revenue (with public health benefits compensating only over the long term) can create a strong disincentive for a sudden ban. To date, only Bhutan has introduced such a ban, in 2004. Thus, although the endpoint of a total ban is highly desirable, the political reality is that it is only by a phased, long-term introduction that such a ban is likely to be achieved.

\section{Non-profit control of supply}

An interesting proposal for a long-term phasing-in of a total ban has been made by Callard et al ${ }^{21}$ It is pointed out that: "The elimination of profit driven behaviour from the supply of tobacco would enhance the ability of public health authorities to reduce tobacco use.' This observation leads to a proposal to transfer responsibility for manufacturing and supplying tobacco to an enterprise with the mandate to achieve a timetabled reduction in tobacco. If enacted and consistently maintained, such a policy indeed has the potential to achieve the eventual elimination of tobacco. However, one suspects that few countries have the political appetite for taking on a role in cigarette distribution, especially as this entails buying out/nationalising existing corporations (at considerable expense to the taxpayer) in order to take over their purveying of a harmful product. In those countries, such as France and China, where such a role already exists, it seems difficult to muster the political courage (and sacrifice of revenue) needed for the state enterprise to reduce such sales by decree. The problem for governments in this situation is somewhat similar to that in respect of tobacco taxation: in principle, it is possible to increase tobacco prices sufficiently steeply year-by-year so as to dramatically reduce demand. However, there are always revenue apprehensions that weigh against dramatic reduction of sales volumes, whether supply-induced or demand-induced. Thus, the campaign for reducing tobacco sales becomes an ongoing event, subject to the prevailing political mood and economic circumstances. Our preference is instead for a single, simple, once-and-for-always measure.

\section{THE PROPOSAL}

We propose, alongside current under-age bans, the introduction of laws banning the provision of tobacco to any citizen born in or after a specific year, suggesting the year 2000 as it is convenient for recall by all parties. The proposal introduces the concept of tobacco-free generations that will never legally be able to take up the harmful habit of smoking, at any age.

\section{DISCUSSION}

Here, we explore some of the main issues raised by the proposed measure.

\section{Simple phase-out}

Ultimately, this proposal will lead to the phasing-out of tobacco provision, without the short-term disruption that makes a sudden ban impracticable. It is a simple, at-a-stroke initiative that removes the risk of being hostage to future changes in political or economic climate. Indeed, in many countries it can be accomplished merely by rewording existing minimum-age legislation-for example, by replacing the expression 'a person below the age of 18 years' by 'a person below the age of 18 years or a citizen born on or after 1 January 2000'. (We discuss below why the word 'citizen' is introduced here.)

\section{Rite of passage}

If there is no longer an age at which tobacco may legally be obtained, it will cease to be a rite of passage. There will also be a change from the perception that smoking is a right of the adult that youths would want to emulate.

\section{Disruption to stakeholders}

Our proposal minimises immediate hardship to tobacco stakeholders. Those currently legally smoking maintain the legal right to continue. There is alignment with tobacco industry assertions that they do not seek to attract new smokers, only to keep their existing market share ${ }^{22} 23$-for example, from the BAT Malaysia website Oct 2005:

At British American Tobacco, we have long accepted that smoking is risky. Our business is not about persuading people to smoke; it is about offering quality brands to adults who have already taken the decision to smoke.

We do not want children to smoke and we actively support programmes to prevent and reduce under-age smoking.

Moreover, employees of tobacco-related industries have time to seek re-employment. This of course includes tobacco executives who might (one hopes) feel less urgency in lobbying against measures whose impact is perceived to be negligible during their own time in the boardroom. Also, government tobacco excise revenue would not show an alarming immediate decrease.

\section{Implementation}

The proposal has greater ease of implementation compared to the current measures. Attaching the ban to a fixed birth year removes the potential inaccuracies in mental calculation across the population, boosting the willingness and ease of enforcement. Identity document checks are already acceptable to the public in the purchases of cigarettes and alcohol, as well as (in Singapore) of mobile telephone subscriber identity module 
(SIM) cards as an anti-terrorism measure. Nevertheless, because vendors have an economic incentive to ignore the law if they believe it is not being adequately enforced, enforcement will remain an issue. Unlike current minimum-age controls however, its difficulty will decline over time, as there is a progressively widening age gap between impressionable young teenagers and those legally able to smoke: a 15-year-old who is keen to be thought 18 is rather less enthusiastic to be seen mimicking 30year-olds!

\section{Tourism}

In societies (such as Singapore) where tourism is an important industry, the distinction between denying tobacco provision to citizens and to others becomes significant. Production of a foreign passport should make it easy for a foreigner to prove that $\mathrm{s} /$ he is exempt from the prohibition.

\section{Immigration}

A related matter is that of immigration. In effect, the willingness to forego tobacco becomes a requirement of nationality. This may deter some potential immigrants; on the other hand, others (especially the better educated) would regard it positively. Thus, the net effect is unlikely to be unfavourable. (See Osypuk and Acevedo-Garcia 2010, ${ }^{24}$ which concluded that 'Immigrants and their children may be valuable tobacco control allies given their supportive attitudes toward smoke-free policies.')

\section{Provision versus use}

An issue is whether the ban should be solely on provision (defined in current Singapore minimum age legislation as selling, giving or furnishing) of tobacco products, or whether culpability should extend to the user. Different jurisdictions may have different views of the wisdom of prosecuting children for such an offence. However, once an age of, say, 18 has been reached, there seems to be no reason not to make smokers legally liable for their actions.

\section{Cross-country comparisons}

The proposal is applicable to all societies whether their prevalence of adolescent smokers is high or low. For example, in the 2000 Global Youth Tobacco Survey (GYTS) of the Philippines, $27.1 \%$ of students were reported to be current users of tobacco products $^{25}$ and data from Guindon and Boisclair ${ }^{26}$ show a world prevalence rate of tobacco use of $28.9 \%$. Figure 1 shows the potential impact of this legislation in a situation with a prevalence smoking rate of $30 \%$, with non-smokers increasing from $70 \%$ to $81.7 \%$.

We use Singapore as an example of a country with a low prevalence rate. Surveys done by a quasi-government institution indicate that $9 \%$ of $13-16$-year-olds had smoked at least once in the preceding 30 days $^{27}$ and that $13.6 \%$ of the adult population were daily cigarette smokers in $2007 .{ }^{5}$ The assumptions of these graphs include an initial percentage of tobacco users of $10 \%$, a constant annual birth rate of $1.35 \%$ in a total resident population of 3.3 million, and a projected adult population of 2.4 million (defined as individuals at and above 18 years of age). With this proposal, figure 2 estimates a $4 \%$ increase in non-smokers from $90.0 \%$ to $93.9 \%$ of all those 18 years old and above. In a lowprevalence country, this rise, albeit not dramatic, is a firm policy stand against tobacco. In the high prevalence example, the percentage increase of $11.7 \%$ is threefold. Of course, these gains assume no additional contribution from other measures, such as those currently recommended by the World Bank, the WHO FCTC treaty and the WHO TFI's MPOWER package, ${ }^{4} 2829$ which our

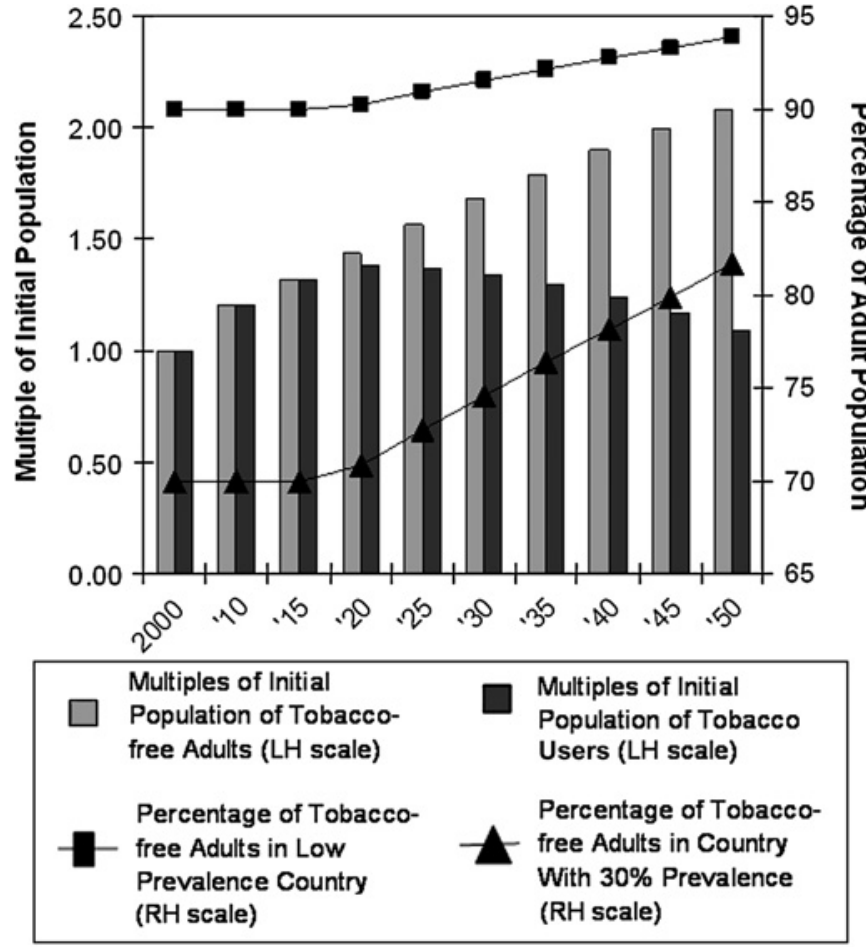

LH = Left hand

RH = Right hand

Figure 1 The potential impact in a country with $30 \%$ adult tobacco users.

proposal is intended to supplement, not replace. In combination with such measures, the improvement is likely to be even greater.

Other intangible factors that differ between countries will also affect the implementation of such a proposal. For example, Singapore is a small city-state with a well established infrastructure where disseminating information and law enforcement is relatively easier, compared to larger, less developed countries. Also, with a high proportion of educated population, public health messages regarding the reason behind the proposal

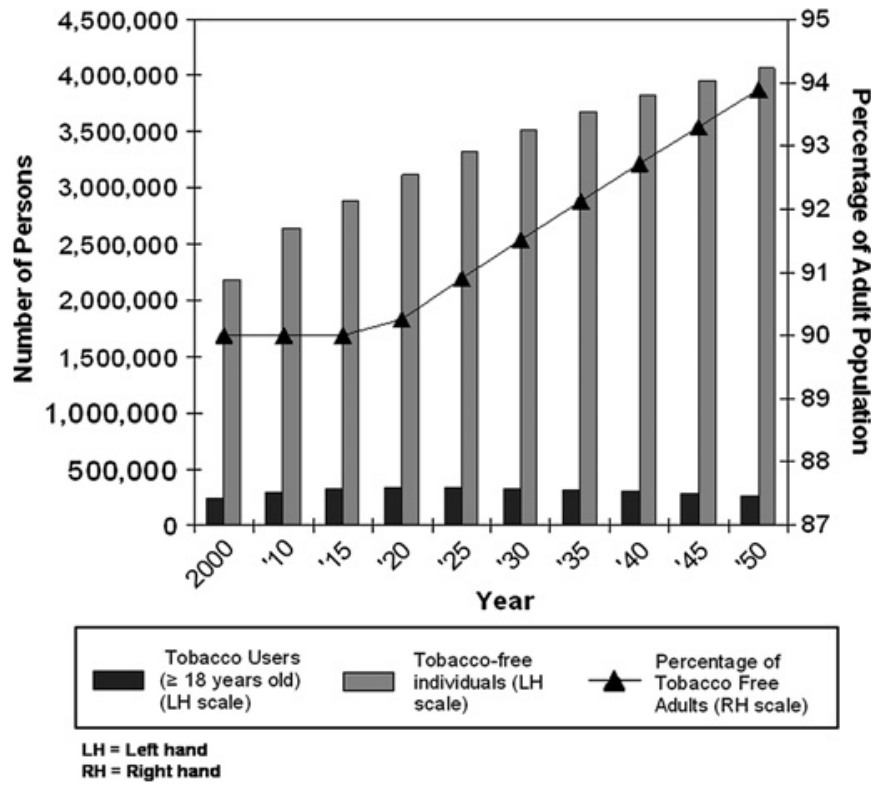

Figure 2 The potential impact of modification in a country with low prevalence $(10 \%)$ of tobacco users. 
and the adverse health consequences of smoking may be better received and translated into putting the proposal into action. The authors acknowledge that factors such as the above will lead to varying experiences among the countries that implement the proposal. It is therefore desirable that the proposal first be implemented in countries where it already meets with public support. Their success could then serve as a model for others.

\section{Demonstration effect}

Probably the greatest weakness of the proposal is that it does not directly address those adults who are already smoking, and whose lives and health are thereby at risk. However, even in this regard there is a positive aspect-namely, the 'demonstration effect': the clear message that a society is moving towards a tobacco-free state is a strong signal to those members contemplating their own habits. This perception of peer pressure is a contributing factor to the positive effects of bans on smoking in workplaces, restaurants and places of entertainment. ${ }^{30} 31$

\section{Decisions for children}

A potential opposition is the view that we would be making unfair decisions for our children. However, the principle of protection of future generations can draw a parallel from governments introducing mandatory vaccination (or fluoridation of state-supplied water) because the long-term future health benefits and savings in healthcare cost clearly outweigh the risks. As with vaccination policies, we believe the entire healthcare industry would strongly support the measure, having seen the anguish of families losing a loved one to the ills of tobacco, and the consumption of national resources to treat the preventable tobacco-related epidemic.

\section{Acceptability}

Nevertheless, the issue of public acceptability of our proposal is an important one, given that governments are naturally reluctant to move too far out of step with public opinion. We therefore felt it desirable to conduct a survey of opinion in Singapore, where the authors of this article are based.

\section{SINGAPORE POPULATION SURVEY ON THE PROPOSAL Methods}

As part of the Lung Cancer Awareness Month 2007 in Singapore, the Singapore Lung Cancer Awareness Study 2007 was conducted to assess the public's perceptions and understanding of the illness. The study also examined the public mindset regarding the link between lung cancer and smoking, in particular passive smoking, and attitudes towards protecting children from access to cigarettes. For the purposes of this survey, we concentrated on tobacco use in the form of cigarette smoking, this being the most common and recognised form. A doorto-door household survey was conducted on a total of 500 Singaporeans and permanent residents aged between 18 and 65 years. All the interviews were completed during the period 20 July to 13 August 2007. Households were selected by stratified cluster sampling, with respondents within households then chosen randomly by Kisch grid. The cohort profile obtained in general closely resembled that of data supplied by an independent research agency based on material from Singapore Population Trends 2006. The percentage of population by age was calculated by proportioning from this demographic data. The population proportion of smokers was obtained from the
National Health Survey 2004 carried out by the Singapore Health Promotion Board (table 1). ${ }^{32}$ The distribution of smokers differed significantly from the National Health Survey 2004 data $(p<0.001)$. The discrepancy lay in the over-representation of smokers in the sample, which would be expected to have the effect of reducing the sample's disapproval of cigarette consumption relative to the general population.

Among a battery of 28 questions relating to such matters as public awareness of cancer, two key questions were put (without elaboration) to the sample population:

1. How important is it to prevent today's children from ever taking up smoking? (figure 3)

2. Would you support a proposal to prevent tobacco being made available to Singaporeans born in and after the year 2000? (figures 4 and 5)

\section{Results}

This survey shows that a clear majority (more than 70\%) support the proposal. In Singapore, there is already a strong antitobacco climate, and the community appears ready to move in the direction of supporting stronger measures against cigarette smoking. For example, the Singapore National Environment Agency's 2005 electronic-consultation forum received 91\% support in a poll for a smoking ban in hawker (food) centres, $90 \%$ for coffee shops and $83 \%$ for entertainment outlets. ${ }^{33}$

Table 1 Profile table of study cohort compared to population data $†$

\begin{tabular}{lll}
\hline Demographics & $\begin{array}{l}\text { Sample } \\
(\mathbf{n}=\mathbf{5 0 0})\end{array}$ & Population 2006† \\
\hline Age & & \\
$18-25$ years & $20.4 \%$ & $20.6 \%$ \\
$26-35$ years & $24.0 \%$ & $22.9 \%$ \\
$36-45$ years & $23.0 \%$ & $25.2 \%$ \\
$46-55$ years & $21.6 \%$ & $20.9 \%$ \\
$56-65$ yers & $11.0 \%$ & $10.3 \%$
\end{tabular}

$\begin{array}{lll}56-65 \text { years } & 11.0 \% & 10.3 \%\end{array}$

$\begin{array}{lll}\text { Gender } & & \\ \text { Male } & 49.8 \% & 49.5 \% \\ \text { Female } & 50.2 \% & 50.5 \%\end{array}$

Smoking status

Smoker

Non-smoker

$18.0 \%$

$12.6 \% *$

Occupation

Professionals, managers, executives $\quad 21.7 \% \quad$ NA

and businessmen/women

White collar

$19.4 \%$

Blue collar

$17.6 \%$

Student/uniformed staff

$24.5 \%$

Others (eg, housewife, retiree)

$16.8 \%$

Education

At most primary $\quad 12.0 \%$

At most secondary

$45.1 \%$

A levels/polytechnic

$27.3 \%$

Degree and above

$15.6 \%$

$-$

Housing type

$\begin{array}{lll}\text { Public-built } 1-4 \text { rooms } & 66.6 \% & 61.1 \%\end{array}$

Public-built $>4$ rooms $\quad 16.6 \% \quad 21.7 \%$

Private-built

$16.8 \%$

$17.2 \%$

*National Health Survey 2004 for Singaporeans and Permanent Residents aged 18-69 years old.

†As calculated by independent research agency (Research plus). 


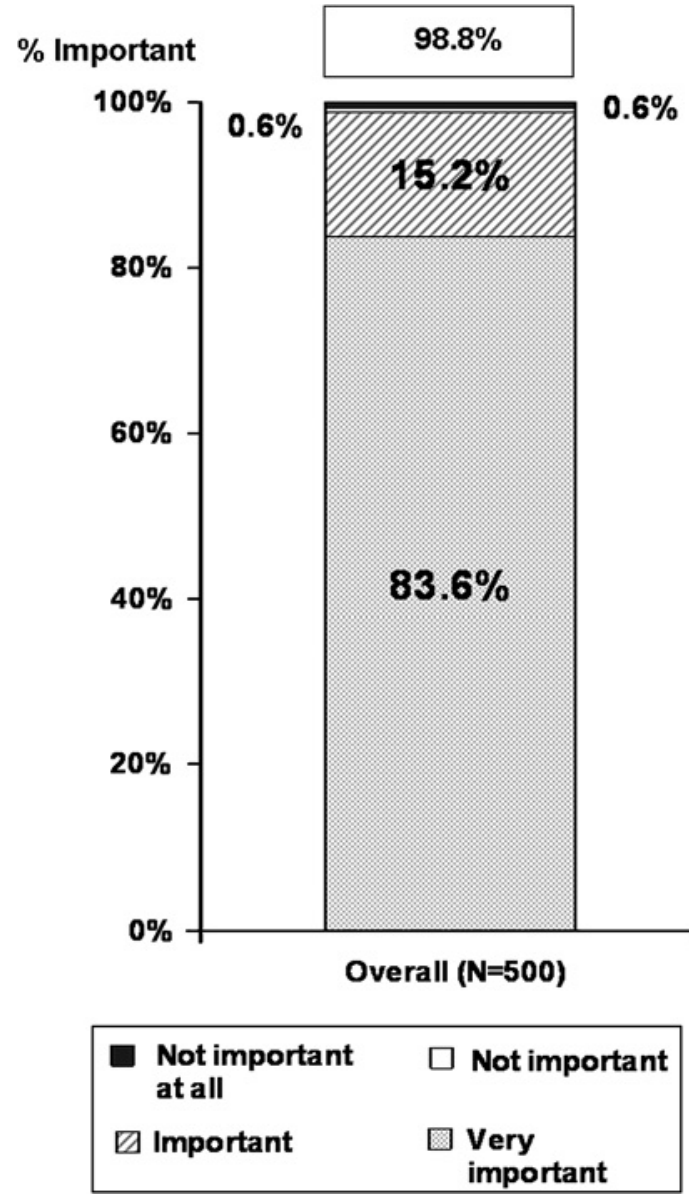

Figure 3 Response regarding importance of preventing children from ever taking up smoking.

Objections raised tended to be in the context of the overall population, not with respect to those born in or after the year 2000. The commonest reason cited was the unfairness of such legislation on an individual's freedom. The above study shows that fewer than $11 \%$ of the total population surveyed spoke of the proposal as unduly impinging on personal rights and freedom. Perhaps this low percentage is because the proposed modification is not an immediate total ban, and does not affect existing tobacco users, but instead only subsequent generations. The study scope does not allow us to comment in depth on actual economic effects, which may be an area for further investigation by the relevant bodies.

The survey showed that $98.8 \%$ (modified Wald 95\% CI 97.3\% to $99.5 \%$ ) of the respondents, including smokers, felt that it was important (or 'very important') to prevent children from ever taking up smoking (figure 3 ). The unequivocal approval rate was evident despite the apparent over-representation of smokers in the sample population.

Of the respondents, $70.4 \%$ (95\% CI 66.3 to $74.2 \%$ ) supported the proposal of a smoking ban for individuals born in or after the year 2000 (figure 4).

With no prior similar studies, it is noteworthy that both smokers and non-smokers show strong support for the proposal (smokers $60.0 \%$, non-smokers $72.7 \%$ ), and likewise when stratified by those with children (71.5\%) compared to those with no children $(69.0 \%)$. (Respective $95 \%$ CIs are: no children: $62.7 \%$ to $74.7 \%$; with children: $65.8 \%$ to $76.8 \%$; smokers: $49.7 \%$ to $69.5 \%$; non-smokers: $68.2 \%$ to $76.8 \%$ ) (figure 5 ).

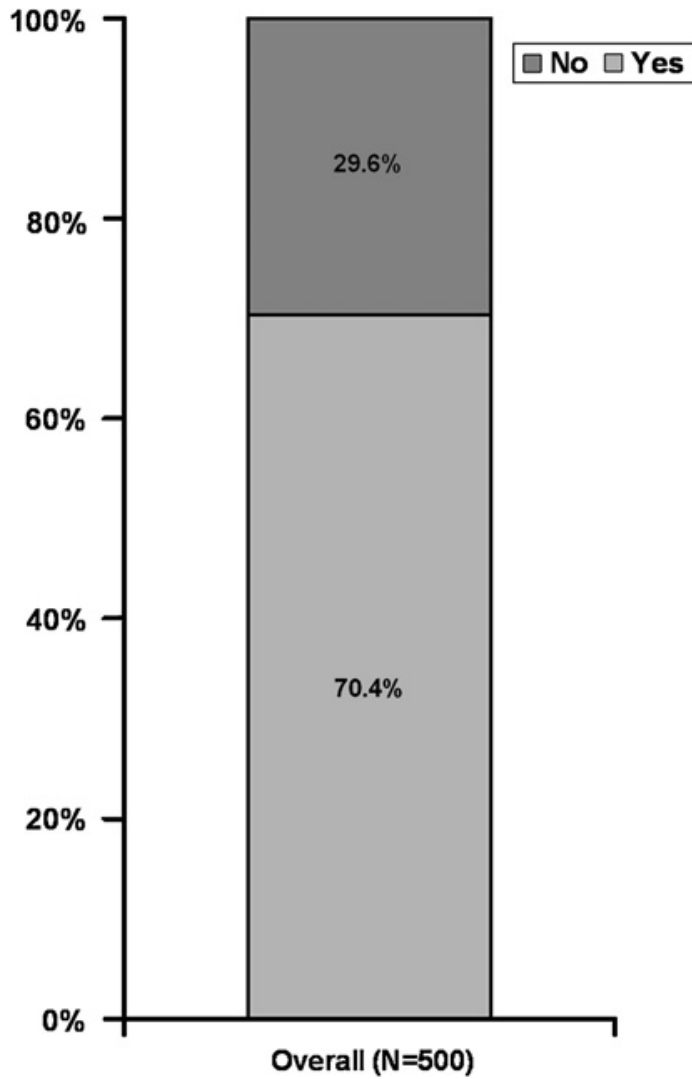

Figure 4 Percentage support for smoking ban for individuals born in or after the year 2000 .

The main objections cited in a free response section were that it impinges unfairly on human rights and freedom, perceived ineffectiveness, the opinion that a total ban is too extreme, and loss of revenue (table 2).

\section{Conclusion}

Our proposal to ban tobacco provision to individuals born in or after the year 2000 is a feasible next step in reducing tobacco consumption. It strikes against the perception of cigarette smoking as a rite of passage. Other benefits include relative ease of implementation, and effectively demonstrating society's stand against cigarettes. By taking the form of a total ban phased-in over the long term, it bears in mind the interests of the various stakeholders, from the government to the tobacco and healthcare industries to the public (including those presently smoking). From our perspective, saving lives and healthcare costs take pre-eminence. We are greatly encouraged by the strong public endorsement of our proposal in Singapore, even among current tobacco users.

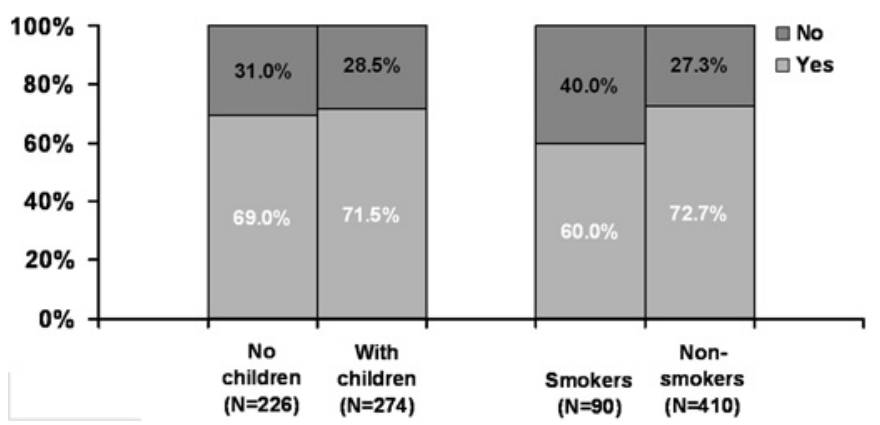

Figure 5 Percentage support for smoking ban by sub-segments. 
Table 2 Objections cited by respondents who did not support proposal, by percentage

\begin{tabular}{lc}
\hline Top $\mathbf{5}$ reasons for disagreeing with proposal $(\mathbf{n}=\mathbf{5 0 0})$ & $\%$ of responses \\
\hline It is an unfair act (eg, no human rights and freedom) & $10.8 \%$ \\
It will not reduce cigarette use & $7.8 \%$ \\
The government will lose a source of revenue from tobacco & $2.2 \%$ \\
Total ban on smoking and sale of tobacco is too extreme & $2.0 \%$ \\
Smokers will find other ways to obtain cigarettes & $2.0 \%$
\end{tabular}

\section{What is already known on this subject}

Although it is widely appreciated that, if submitted now, tobacco products would fail to be approved by health authorities, by historical accident they are generally treated as legal products for adults. Largely because of the addictive nature of the product, an immediate ban is perceived as unacceptably harsh. Numerous restrictive measures have been implemented worldwide, with a certain amount of success. Nevertheless, a clear path for getting from the present situation to a tobacco-free society has so far proved elusive.

\section{What this study adds}

This paper introduces and considers a new strategy for phasing out tobacco usage, by proposing that individuals born in or after the year $\mathbf{2 0 0 0}$ have their supply of tobacco restricted. The paper discusses why this proposal is likely to change community attitudes to smoking, and explores issues of implementation. A survey conducted in Singapore reveals strong community support for the initiative, of more than $70 \%$ overall, including $60 \%$ among smokers interviewed.

Acknowledgements We declare that all authors had full access to all of the data in the study and take responsibility for the integrity of the data and the accuracy of data analysis. The authors are very grateful to the referees for their insightful comments.

\section{Competing interests None}

Contributors $\mathrm{H}-\mathrm{NK}$, principal investigator; DK, writer, figures, literary search; $\mathrm{AJB}$, writing, analysis, mathematical adviser; $\mathrm{YC}$, writer, resource and contact liaison, literary search; PN, writing, data analysis.

Provenance and peer review Not commissioned; externally peer reviewed.

\section{REFERENCES}

1. Quah E, Tan KC, Saw SLC, et al. The social cost of smoking in Singapore. Singapore Med J 2002:43:340-4.

2. Sung HY, Wang L, Jin S, et al. Economic burden of smoking in China, 2000. Tob Control 2006:15(Suppl 1):i5-11.

3. Centers for Disease Control and Prevention (CDC). Smoking-attributable mortality, years of potential life lost, and productivity losses-United States, 2000-2004. MMWR Morb Mortal Wkly Rep 2008;14;1226-8.
4. WHO report on the Global Tobacco Epidemic, 2008. http://www.who.int/ tobacco/mpower/en. (accessed 15 Dec 2009).

5. National Smoking Control Campaign 2009. http://www.hpb.gov.sg/news/article. aspx?id=5276. (accessed 13 Dec 2009).

6. Willemsen MC, Zwart W. The effectiveness of policy and health education strategies for reducing adolescent smoking: a review of the evidence. J Adolesc 1999:22:587-99

7. Jarvik ME. The major evidence for nicotine's addictiveness. Psychopharmacology 1995:117:18-20

8. National Cancer Institute. Changing adolescent smoking prevalence (smoking and tobacco control monograph no. 14). Bethesda, MD: National Institutes of Health Pub. No. 02-5086, 2001.

9. Tan ASL, Arulanandam S, Chng CY, et al. Overview of legislation and tobacco control in Singapore. Int J Tuberc Lung Dis 2000:4:1002-8.

10. Glantz SA. Editorial. Preventing tobacco use: the youth access trap. Am J Public Health 1996;86:156-7.

11. Vardavas Cl, Connolly G, Karamanolis K, et al. Adolescents perceived effectiveness of the proposed European graphic tobacco warning labels. Eur $\mathrm{J}$ Public Health 2009;0:ckp015v1-ckp015; 19:212-17.

12. Hammond D, Fong GT, McNeill A, et al. Effectiveness of cigarette warning labels in informing smokers about the risks of smoking: findings from the International Tobacco Control (ITC) Four Country Survey. Tob Control 2006;15:iii19-25.

13. Consultation on under-age sale of tobacco 2006. http://www.dh.gov.uk/en/ Consultations/Closedconsultations/DH_4139361 (accessed 2 Dec 2007).

14. Jacob M. Editorial. Health Educ J 19989:48:102.

15. Smoke free movies. http://smokefreemovies.ucsf.edu/problem/bigtobacco.html (accessed 29 Dec 2009).

16. Scene Smoking. http://www.scenesmoking.org (accessed 29 Dec 2009).

17. Forster JL, Wolfson M. Youth access to tobacco: policies and politics. Ann Rev Public Health 1998;19:203-35.

18. Stead LF, Lancaster T. A systematic review of interventions for preventing tobacco sales to minors. Tob Control 2000;9:169-76.

19. "Easy for under-18 youths to buy cigarettes" Straits Times 2005

20. "Underage Smoking - more young people caught lighting up in first two months" Straits Times 2008.

21. Callard C, Thompson D, Collishaw N. Transforming the tobacco market: why the supply of cigarettes should be transferred from for-profit corporations to non-profit enterprises with a public health mandate. Tob Control 2005:14:278-83.

22. Reynolds RJ. Memo from Don Albert to Brenda Follmer 19 May 1993. Bates No. 515228723/8723. Tob Int. http://legacy.library.ucsf.edu/tid/amb03d00 (accessed 27 Aug 2003)

23. Wen CP, Chen T, Tsai YY, et al. Are marketing campaigns in Taiwan by foreign tobacco companies targeting young smokers? Tob Control2005:14:38-44.

24. Osypuk TL, Acevedo-Garcia D. Support for smoke-free policies: a nationwide analysis of immigrants, US-born, and other demographic groups, 1995-2002. Am Public Health 2010;100:171-81.

25. 2000 Global Youth Tobacco Survey Philippines. http://www.cdc.gov/tobacco/ Global/gyts/factsheets/wpro/2000/philippines_factsheet.htm laccessed 25 Nov 2008)

26. Guindon GE, Boisclair D. Past, Current and Future Trends in Tobacco Use, HNP Discussion Paper (Economics of Tobacco Control Paper No, 6). Washington, DC: World Bank, 2003.

27. Singapore Student Health Survey 2006. http://www.hpb.gov.sg/uploadedFiles/ HPB Online/Publications/student-health-survey-2006c.pdf (accessed 4 Dec 2008).

28. Curbing the Epidemic. Washington, DC: Governments and the Economics of Tobacco Control, World Bank, 1999. http://www1.worldbank.org/tobacco/book/html/ chapter4.htm (accessed 28 Dec 2009).

29. World Health Organization Framework Convention on Tobacco Control. http:// whqlibdoc.who.int/publications/2003/9241591013.pdf (accessed 28 Dec 2009).

30. Grassi MC, Enea D, Ferketich AK, et al. A smoking ban in public places increases the efficacy of bupropion and counseling on cessation outcomes at 1 year. Nicotine Tob Res 2009;11:1114-21.

31. Thomson G, Wilson N, Edwards R, et al. Should smoking in outside public spaces be banned? Yes. BMJ 2008;337:a2806.

32. Singapore National Health Survey 2004. http://www.moh.gov.sg/mohcorp/ publicationsreports.aspx?id=2984 (accessed 14 Dec 2008).

33. Singapore National Environment Agency E-consultation: Extend the smoking ban to more public places in Singapore. http://app.reach.gov.sg/olcp/asp/ocp/ ocp01d1.asp?id=2245 (accessed 10 Nov 2008). 